\title{
Negative skin friction on piles: a simplified analysis and prediction procedure
}

\author{
E. E. ALONSO*, A. JOSA ${ }^{\dagger}$ and A. LEDESMA ${ }^{\dagger}$
}

\begin{abstract}
In order to describe the interaction between a single pile and a consolidating soil a stress transfer approach at the interface is proposed. The non-linear, plastic character of the shear stress acting on the pile shaft and the adequate modelling of unloading and cyclic behaviour are properly incorporated through a 'shooting' solution procedure of the equilibrium equations. The whole problem is formulated in dimensionless terms both for external uniform loading conditions and for changes in piezometric levels. The formulation and the computational procedure developed are fairly general and may accommodate arbitrary layering and complicated loading sequences. In many practical situations the whole length of the shaft-soil interface has reached a limiting shear stress state except for a narrow zone around the neutral point. It is then possible to derive analytical solutions for the main design parameters. Their usefulness has been checked through several well-documented case records.
\end{abstract}

L'article propose de prendre le transfert de contraintes interfacial afin de pouvoir décrire l'interaction entre un pieu individuel et un sol consolidant. La nature plastique non-linéaire de la contrainte de cisaillement agissant sur le fût du pieu et le modelage approprié du déchargement et du comportement cyclique sont incorporés de façon convenable par le moyen d'une méthode qui procède par tâtonnements (shooting) pour résoudre les équations d'équilibre. Le problème est formulé dans des termes sans dimensions aussi bien pour les conditions de chargement uniformes externes que pour les changements des niveaux piézométriques. La formulation ct la méthode de calcul qui ont ćtć developés sont de nature assez générale et peuvent inclure la disposition arbitraire en couches et des suites compliquées de chargement. Dans beaucoup de situations pratiques la longueur entière de l'interface fût/sol a atteint un état limitant de contrainte de cisaillement à l'exception d'une zone étroite autour du point neutre. Il est alors possible de dériver des solutions analytiques pour les paramètres principaux de construction. Leur utilité a été contrôlée par moyen de plusieurs cas de construction bien documentés.

\section{INTRODUCTION}

Present procedures for the predictions of negative downdrag forces on single piles fall into the

Discussion on this Paper closes on 1 January 1985. For further details see inside back cover.

* Professor of Geotechnical Engineering, Polytechnic University of Barcelona.

† Ingeniero de Caminos, Canales y Puertos, Barcelona. following two broad categories.

(a) A distribution of friction stresses along the pile shaft is proposed by some empirical reasoning. The integration of these stresses gives the desired total downdrag. Both total and effective stress analyses can be accommodated. Analyses of this type have been given, for instance, by Terzaghi \& Peck (1948, 1967), Elmasry (1963) and Broms (1977).

(b) Elastic and elasto-plastic analysis of the pile-soil interaction. Early elastic analyses based on integral equation methods and existing analytical solutions for point loads within the half-space were provided by Salas \& Belzunce (1965), Begemann (1969) and Verruijt (1969); recent more extensive work along these lines has been performed by Poulos \& Davis (1972, 1975). Pile-soil slip can be introduced in a simplified way into these analyses. Finite element procedures have also been used to investigate negative skin friction by Walker \& Darvall (1973) and Boulon, Desrues \& Foray (1978), among others.

All these methods have shortcomings. Some of them are perhaps too crude and may be incapable of being used in conjunction with settlement or deformation analyses. Elastic solutions are not well suited to represent the complex stress transfer phenomena at the interface and it is not easy to include non-homogeneous soil profiles. The finite element solutions are expensive for preliminary design and not available in parametric form.

It was felt that some alternative simple solution method compatible with the fundamental phenomena would give easy and cheap design procedures for a fast, yet accurate, estimation of negative skin loads and deformations. Moreover, if the analysis could be carried through in dimensionless form, the derived solutions could be applied for a wide variety of situations.

In order to fulfil these requirements the transfer function approach, successfully applied to the analysis of piles under external load (Seed \& Rcese, 1957; Kezdi, 1960; Reese, 1964; Coyle 


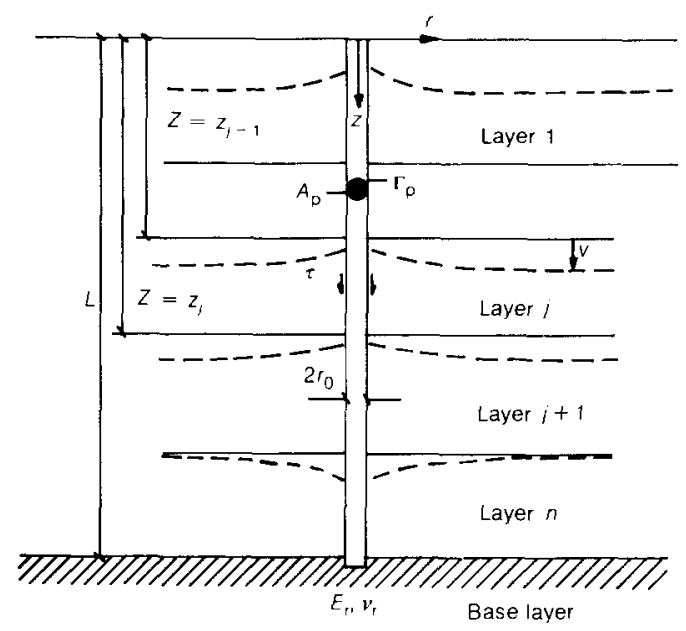

Fig. 1. Diagram of the basic problem

\& Reese, 1966; Reese, Hudson \& Vijayvergiya 1969) appears to be a powerful and flexible method.

In this Paper a model to compute loads and deformations of single piles subjected to downdrag effects based on the transfer function approach is derived. Simple numerical solutions procedures are developed for fairly general conditions (non-linear stress-strain behaviour at the pile-soil interface, non-homogeneous soil conditions and two types of mechanism inducing consolidation: external loading and changes in piezometric head). For a specific bilinear shape of the transfer function a dimensionless formulation of the governing equilibrium and compatibility equations is presented. For advanced consolidation stages analytical dimensionless closed form solutions are given. They can be used for design purposes. The derived closed form solutions are checked against several welldocumented field records.

\section{TRANSFER FUNCTION APPROACH}

The equilibrium of an elastic pile element along its axis can be written (Fig. 1) as

$$
-E_{\mathrm{p}} \frac{\mathrm{d}^{2} \omega}{\mathrm{d} z^{2}}=\frac{\Gamma_{\mathrm{p}}}{A_{\mathrm{p}}} \tau
$$

where $\omega$ is the vertical displacement of the pile shaft, $E_{\mathrm{p}}, \Gamma_{\mathrm{p}}$ and $A_{\mathrm{p}}$ are the modulus of elasticity, the perimeter and cross-sectional area of the pile, and $\tau$ is the tangential stress exerted by the soil.

If the deformation of the soil adjacent to the pile is idealized as a pure shearing of concentric cylinders, the variations in vertical stress along $z$ in the vicinity of the pile are neglected if com- pared with the shear stress gradients in the radial direction, and the radial displacement is also ignored, it can be shown (Randolph \& Wroth, 1978) that the shear stress acting on the pile shaft is a direct function of the vertical pile displacement. All the assumptions mentioned are probably met quite closely. The first one emerged from the finite element analysis performed by Frank (1975), even if soil dilatancy is taken into account. However, equilibrium and compatibility in the radial direction, under elastic conditions, almost has no influence in the overall pile behaviour according to Butterfield \& Banerjee (1970).

Under this set of conditions the equation of equilibrium of a soil element in the vertical direction, expressed in a cylindrical system of co-ordinates (Fig. 1), becomes

$$
\frac{\partial \tau_{r z}}{\partial r}+\frac{\tau_{r z}}{r}=0
$$

Introducing the shear modulus of the soil $G$ gives

$$
\tau_{r z}=G \gamma_{r z}=G \frac{\partial s}{\partial r}
$$

where $s$ is the vertical displacement of the soil. The solution of equations (2) and (3) in terms of $s$ is

$$
s=\frac{1}{G} f(z) \ln r+h(z)
$$

where $f(z)$ and $h(z)$ are two arbitrary functions. If no soil-pile slip is allowed, the boundary conditions are

$$
s=\omega \quad \text { if } \quad r=r_{0} \quad \text { and } \quad s=v \quad \text { if } \quad r=R
$$

where $r_{0}$ is the pile radius, $R$ some (long) distance which corresponds to the end of the pile influence and $v$, the free consolidation settlement at depth $z$. According to equations (3)-(5) the shear stress $\tau$ acting on the pile shaft can be written as

$$
\tau=\frac{G}{r_{0}} \frac{1}{\ln R / r_{0}}(v-\omega)
$$

This expression can be viewed as a special form of a transfer function equation. An obvious generalization would be to write

$$
\tau=\mathrm{f}(v-\boldsymbol{\omega})
$$

Closed form expressions for $v$ can be found under the classical Terzaghi assumptions of onedimensional consolidation theory. For a single layer the vertical displacement at any point 
induced by an external uniform load $\Delta \sigma$ at the surface of a layer of thickness $L$ is

$$
\begin{aligned}
& v(T, Z)=\frac{a_{\mathrm{v}} L \Delta \sigma}{1+e_{0}}\left[1-Z-\sum_{m=0}^{\infty} \frac{8}{(2 m+1)^{2} \pi^{2}}\right. \\
& \left.\times \exp \left(\frac{-\pi^{2}(2 m+1)^{2}}{4} T\right) \cos \left(\frac{2 m+1}{2} \pi Z\right)\right]
\end{aligned}
$$

where $Z=z / L, T=c_{\mathrm{v}} t / L$ is the usual time factor and the uniaxial deformability coefficient $a_{\mathrm{v}} /(1+$ $e_{0}$ ) is assumed to be constant. If the consolidation is induced by piezometric variations $\Delta p_{\omega_{1}}$ and $\Delta p_{\omega_{2}}$ at two frec drainage boundaries (layer thickness $L$ )

$$
\begin{aligned}
& v(T, Z)= \\
& \frac{a_{v} L}{1+e_{0}}\left[\frac{\Delta p_{\omega_{1}}+\Delta p_{\omega_{2}}}{2}-\Delta p_{\omega_{1}} Z+\frac{\Delta p_{\omega_{1}}-\Delta p_{\omega_{2}}}{2}\right. \\
& \quad \times Z^{2}-\left(\frac{\Delta p_{\omega_{1}}+\Delta p_{\omega_{2}}}{2}\right) \sum_{m=1}^{\infty} \frac{1+\zeta(-1)^{m+1}}{1+\zeta} \frac{8}{\pi^{2} m^{2}} \\
& \quad \times \exp \left(-m^{2} \pi^{2} T / 4\right)(1-\cos (m \pi(1-Z))]
\end{aligned}
$$

where $\zeta=\Delta p_{\omega_{1}} / \Delta p_{\omega_{2}}$.

Final settlements corresponding to both types of condition are, respectively, given by

$$
\begin{aligned}
v(Z) & =\frac{a_{\mathrm{v}} L \Delta \sigma}{1+e_{0}}(1-Z) \\
v(Z) & =\frac{a_{\mathrm{v}} L}{1+e_{0}} \\
& \times\left[\frac{\Delta p_{\omega_{1}}+\Delta p_{\omega_{2}}}{2}-\Delta p_{\omega_{1}} Z+\frac{\Delta p_{\omega_{1}}-\Delta p_{\omega_{2}}}{2} Z^{2}\right]
\end{aligned}
$$

The relationships (1), (7) and (8) or (9) define a differential equation for the vertical pile displacement which has to be solved with the appropriate boundary conditions. If $Q$ is the applied external load and $n$ denotes the number of consolidating layers (Fig. 1), they can be written as

$$
\begin{aligned}
& \frac{\mathrm{d} \omega^{1}}{\mathrm{~d} z}=-\frac{Q}{E_{\mathrm{p}} A_{\mathrm{p}}} \quad \text { at } \quad z=0 \\
& \omega^{j+1}=\omega^{j} \quad \text { at } \quad z=z_{j} \\
& \text { for } j=1,2 \ldots n-1 \\
& \frac{\mathrm{d} \omega^{i+1}}{\mathrm{~d} z}=\frac{\mathrm{d} \omega^{j}}{\mathrm{~d} z} \quad \text { at } \quad z=z_{\mathrm{j}} \\
& \text { for } j=1,2 \ldots n-1
\end{aligned}
$$

where $\omega^{j}$ is the vertical displacement of the pile shaft at the layer $j$.

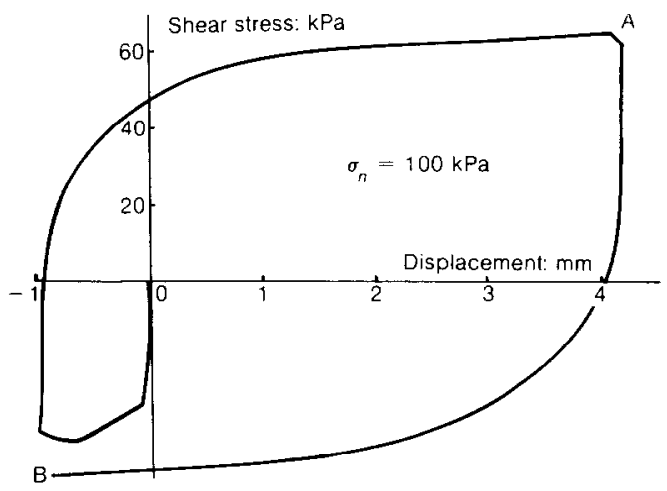

Fig. 2. Drained cyclic direct shear test of the clay-concrete interface

$$
\omega^{n}=\int_{0}^{L} \tau(z) \mathrm{d} z \frac{\pi\left(1-\nu_{\mathrm{r}}\right)}{E_{\mathrm{r}}} \eta
$$

Equation (15) expresses that the soil tip is assumed to act as a rigid punch on the surface of an elastic half-space $\left(E_{\mathrm{r}}, \nu_{\mathrm{r}}\right)$. No interaction between the base layer and the upper consolidating soil is considered. However, the factor $\eta$ is introduced to account for the embedment of the pile tip. Randolph \& Wroth (1978) suggest that for straight piles $\eta$ is probably close to unity. In this Paper the assumption $\eta=1$ has been made.

\section{LABORATORY TEST RESULTS ON THE PILE-SOIL INTERFACE BEHAVIOUR}

Before going into specific proposals for the transfer load relationship (equation (2)), several laboratory tests simulating the interface behaviour were run. They were intended to provide mainly qualitative information. Special attention was given to the reversal alternating stress conditions, likely to occur in some parts of the pile in almost any negative skin friction case, as shown later, and to the development of shear stress for small relative displacements.

A standard $6 \mathrm{~cm}$ square shear box machine was modified to reproduce alternating cycles of shear stress. The lower half of the box was filled with a rather smooth concrete specimen and a remoulded low plasticity silty clay $\left(w_{1}=27 \cdot 8 \%\right.$; $w_{\mathrm{p}}=18 \cdot 8 \%$ ) was consolidated against it. Special care was taken to reduce to a minimum spurious frictions of the box. Their effect was noticeable, however, for confining stresses smaller than $25 \mathrm{kPa}$. Several tests with varying normal stresses (25-200 kPa) and a shearing speed adjusted to ensure drained conditions were run.

A complete loading cycle corresponding to one of these tests is shown in Fig. 2. Despite the well-known interpretation difficulties of this particular type of test some general trends emerged 


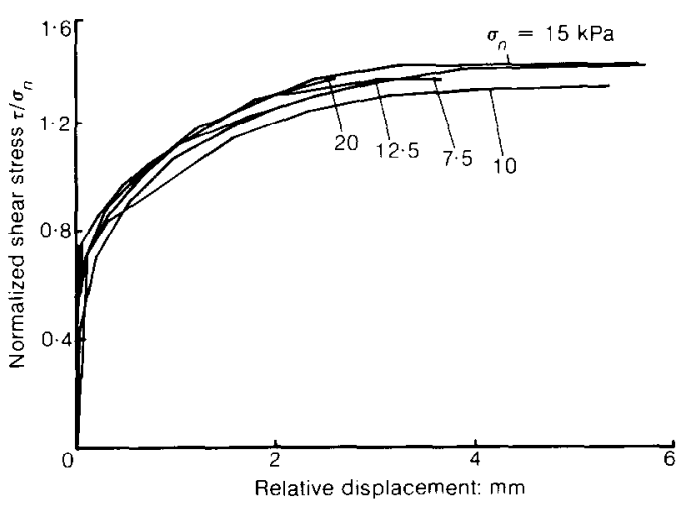

Fig. 3. Relative shear stress-displacement curves for the direct soil-concrete shear tests: first unloading cycle

from the experimental results. Very small relative displacements $(0.2 \mathrm{~mm})$ mobilize in all the tests a high percentage (close to $60 \%$ ) of the limit shear stress, $\tau_{1}$. This result is valid for any loading, unloading and reloading branch of the cyclic test. In addition, a relative displacement of $3 \mathrm{~mm}$ from the point of stress reversal mobilizes up to $95 \%$ of $\tau_{1}$. No significant differences were found on successive stress reversals (up to a maximum of four) as far as relative limit stress $\left(\tau_{1} / \sigma_{\mathrm{n}}\right.$ where $\sigma_{\mathrm{n}}$ is the confining stress $)$ is concerned.

Curves for the first unloading stress conditions (i.e. curve $A B$ in Fig. 2), all referred to the same origin, are plotted in Fig. 3. They correspond to several confining pressures. Some of the conclusions of the test program are readily observed. Also apparent is the linear relationship between limit shearing and confining stresses.

In order to perform a systematic analysis, more easily applied in practice, it is convenient to simplify the stress transfer conditions at the pile shaft. Such a simplification is shown in Fig. 4. The stress transfer function is characterized by two limit shear stress values- $\tau_{l 1}$ and $\tau_{12}$ and two stress-displacement slopes: $\alpha_{1}$ which corresponds to the first branch of the loading history at any particular point of the shaft (either in positive or negative shear) and $\alpha_{2}$ for any subsequent stress reversal.

Alternatively a limiting relative displacement $(v-\omega)_{\text {lim }}$ (Fig. 4) could be used instead of the stress-displacement slope $\alpha_{1}$. In fact there is some experimental evidence which suggests that, for different soil types subjected to shear along pre-defined planes of intense shearing, a peak is reached for displacements of the order of a few millimetres. Lupini, Skinner \& Vaughan (1981) present results for a number of ring shear tests on natural soils (marls, shales, overconsolidated

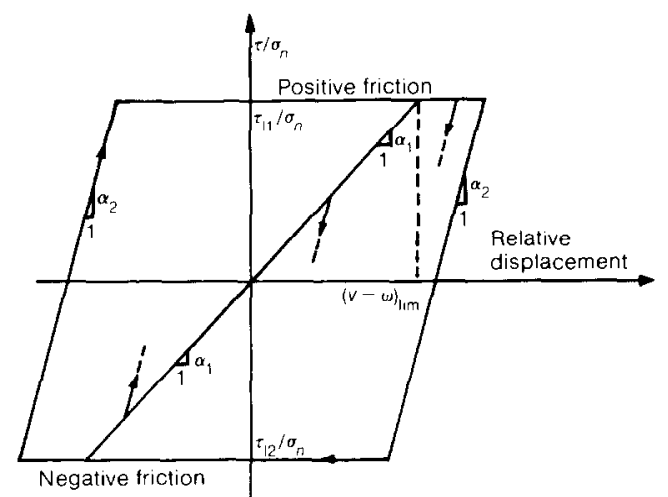

Fig. 4. Simplified transfer function law adopted for the dimensionless formulation

clays and tills). From fig. 4 of their paper it can be concluded that for most cases a displacement of $2-3 \mathrm{~mm}$ is enough to induce the peak strength. Medium to high plasticity clays exhibit brittle behaviour and the residual strength is usually reached for displacements in excess of $100 \mathrm{~mm}$. There is also some evidence (Mitchell, 1976; Littleton, 1976) that the shearing against hard polished surfaces encourages the development of residual strength at small shear displacements.

In an experimental study of skin friction around small-scale model piles in clay, Chandler \& Martins (1982) reported lateral loaddisplacement curves in which the peak was reached, quite consistently, in the vicinity of a displacement of $2 \mathrm{~mm}$ (fig. 7 of their paper). The clay used was a commercial kaolin and the model tests showed brittle effects associated with a decrease in the interface friction angle.

Direct shear tests aimed to simulate the interface between concrete piles and sand were carried out by Clemence \& Brumund (1975). The resulting shear stress-displaccment curves, which did not show any brittle effect, were described by means of hyperbolic equations. Most of the shear stress was developed for very small displacements, usually a fraction of a millimetre. For the range of normal stresses used in the tests $(10-28 \mathrm{kPa})$ the relative displacements necessary to reach $95 \%$ of the ultimate strength range from 1.1 to $2 \mathrm{~mm}$, according to the hyperbolic equations adjusted to the experimental data. Large-scale model tests specifically designed to measure accurately the lateral friction on piles under vertical load were also carried out. The ultimate skin friction was reached for top deflexions of $1.2-1.6 \mathrm{~mm}$.

On the basis of these results it is suggested that the shear displacement necessary to induce 
peak strength at the pile-soil interface will, for most cases, be in the range of 1-3 millimetres. Soil type does not appear to have a major influence on this value. However, medium to high plasticity clays tend to show brittle behaviour and a residual strength is reached for large displacements $(100-400 \mathrm{~mm})$. On the other hand, sandy and silty soils and low plasticity clays do not show any noticeable reduction in peak shear strength with shearing displacement. It has been suggested that the transition between both groups is rather abrupt for clays of similar activity (Lupini et al., 1981). In addition, the similarities observed between shear tests and various model pile tests, as far as limiting displacements necessary to induce full mobilization of shear stress is concerned, indicate that those limiting displacements are also largely independent of pile diameter and may well be regarded as an independent parameter. In an example of negative skin friction distribution, presented later, a simplified bilinear non-brittle transfer function with a limiting displacement of $2 \mathrm{~mm}$ is selected.

It should be emphasized that stress transfer functions defined cither numerically or analytically from field or laboratory tests or the simplified version just described can be incorporated in the solution procedure outlined in the next section. The dimensionless formulation presented later on is, however, based on the simplified law.

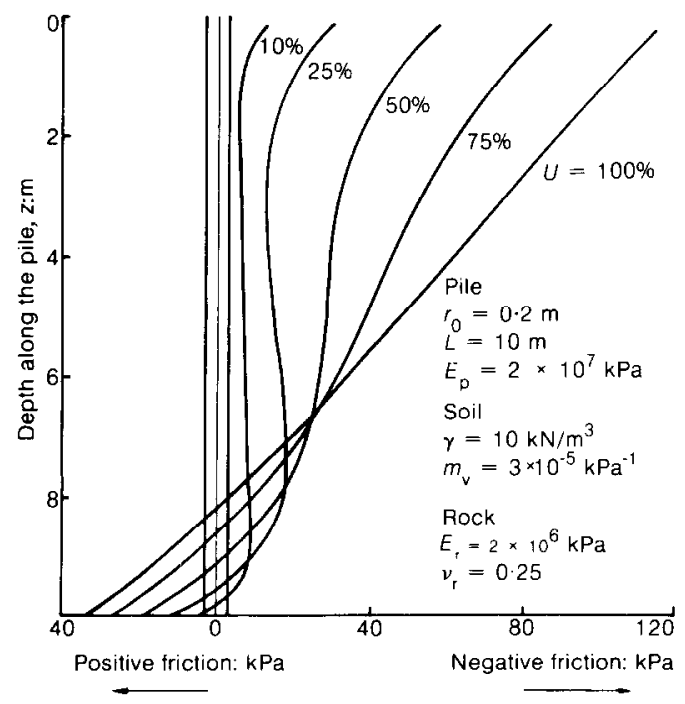

Fig. 5. Evolution of negative skin friction with degree of consolidation for an end bearing pile and linear transfer function; consolidation induced by changes in the upper and lower piezometric levels: $\Delta p_{\omega 1}=10 \mathrm{kPa} ; \Delta p_{\omega_{2}}=20 \mathrm{kPa}$
The process of pile driving and, probably, the excavation associated with cast in situ bored piles takes the shaft-soil interface to an initial limiting residual state with pronounced particle reorientation. In these cases the displacements associated with any future negative or positive stress transfer take place along the $\alpha_{2}$ lines.

\section{SOLUTION PROCEDURE}

A specially simple problem arises when the transfer function is assumed to be linear. It has been shown that this linearity corresponds to elastic behaviour of the soil. Closed form solutions were derived for the shaft shear stresses using the settlement equations (8) and (9). An example is shown in Fig. 5. The distribution of shear stresses along an end bearing pile for varying degrees of consolidation shows that maximum negative shear stresses tend to concentrate in the upper part of the pile where settlements are larger. These results are believed to be of very limited interest in practical situations.

For general transfer functions a numerical solution procedure is needed. A finite difference approximation of equation (1) can be written

$$
\omega_{i+1}=(\Delta z)^{2} \chi \tau_{i}+2 \omega_{i}-\omega_{i-1}
$$

where $\chi$ is a constant $\left(-2 / E_{\mathrm{p}} r_{0}\right.$, if the pile is a cylinder of radius $r_{0}$ ) and $\tau_{i}$ is given by the transfer function at point $i, \tau_{\mathrm{i}}=\mathrm{f}\left(v_{i}-\omega_{i}\right)$.

It has been found that a convenient and powerful procedure for solving the problem for heterogeneous soil profiles and complicated anelastic transfer functions is to consider equation (16) as a marching scheme in conjunction with a 'shooting' method.

Instead of formulating a full set of non-linear equations the solution is found by adjusting successively the initial conditions at the pile top so that convergence is found for the settlement of the pile base. Consider in Fig. 6(a) a distribution of pile downward displacements generated

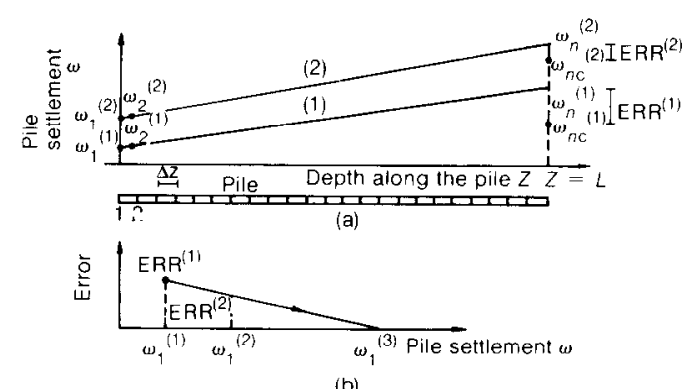

(b)

Fig. 6. Schemes illustrating the shooting method for solution 


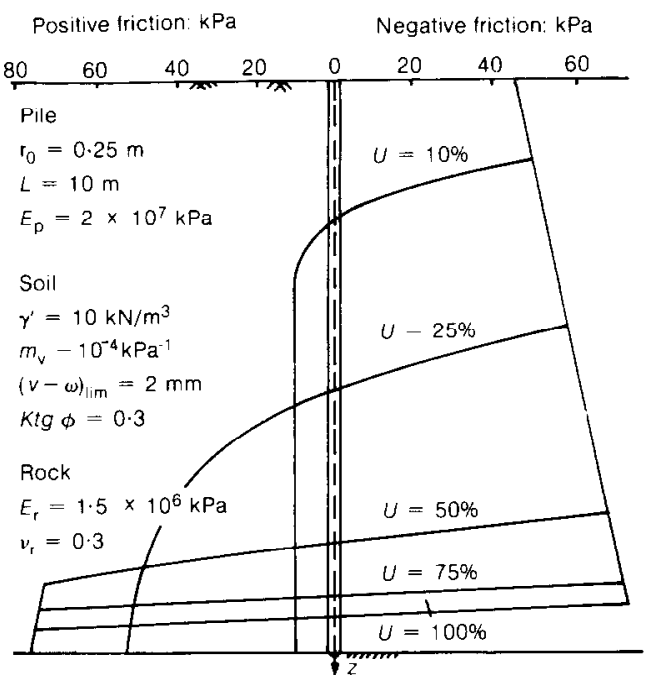

(a)

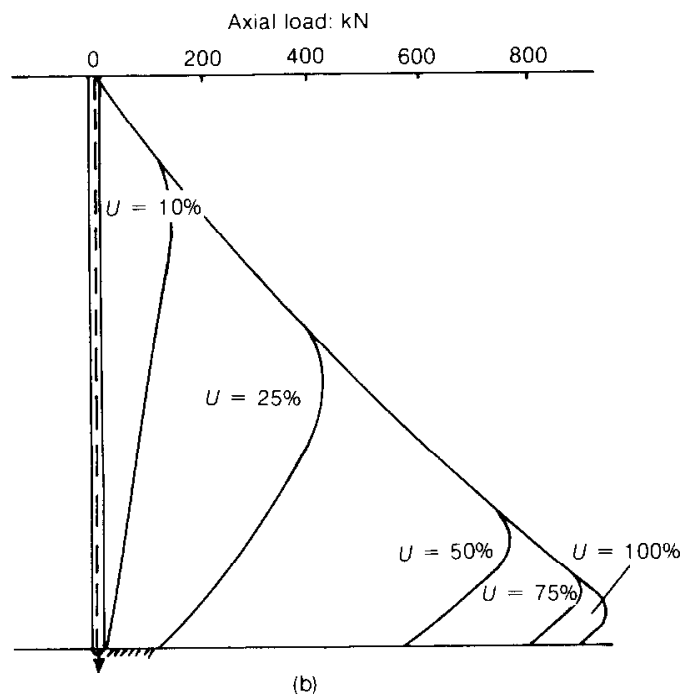

Fig. 7. Evolution of negative skin friction with degree of consolidation for an end bearing pile; consolidation induced by an external uniform load $\Delta \sigma=150 \mathrm{kPa}$. Pervious soil-pile interface: (a) shear test distribution along the pile shaft; (b) total downdrag axial forces; (c) stress histories of some points along the shaft

by equation (16). For an initially assumed pile top displacement $\omega_{1}^{(1)}$, and the following condition at the second point

$$
\omega_{2}^{(1)}=\omega_{1}^{(1)}-\sigma_{\mathrm{Q}} \Delta z / E_{\mathrm{p}}
$$

( $\sigma_{Q}$ is the external unit load acting on pile top and equal to $\left.Q / A_{p}\right)$, repeated use of equation (16) leads to a base settlement $\omega_{n}^{(1)}$. This dis-
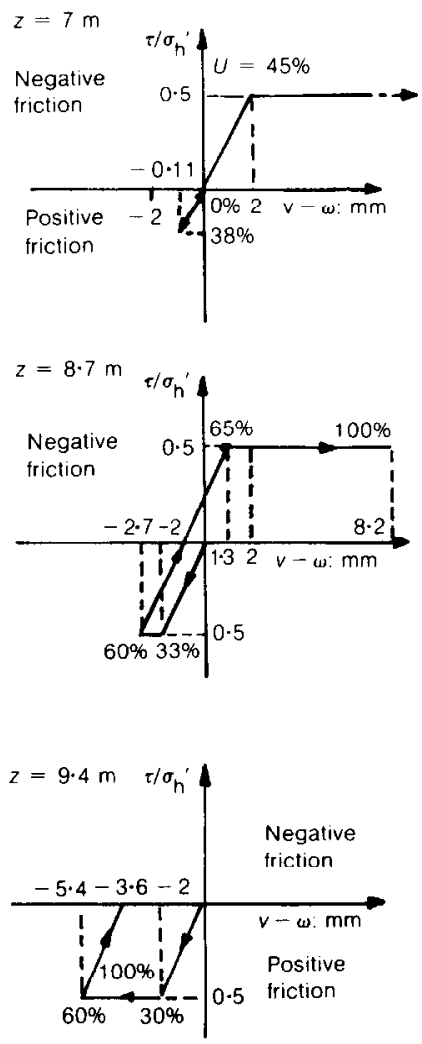

(c)

placement must coincide with the value

$$
\omega_{\mathrm{nc}}^{(i)}=\frac{\pi r_{0}\left(1-\nu_{\mathrm{r}}^{2}\right)}{2 E_{\mathrm{r}}}\left(\sigma_{\mathrm{O}}-\chi E_{\mathrm{p}} \int_{0}^{L} \tau(z) \mathrm{d} z\right)
$$

which is computed through the transfer function and the first approximation of vertical displacements along the pile (curve (1) in Fig. 6(a)). Some crror, $\mathrm{ERR}^{(1)}=\omega_{n}^{(1)}-\omega_{n \mathrm{c}}^{(1)}$ will, however, be induced. Identical procedure is now repeated for a secondly selected initial displacement $\omega_{1}^{(2)}$. The new settlement error at the pile base, ERR $^{(2)}$, will help in finding a new improved guess for the top displacement (Fig. 6(b))

$\omega_{1}^{(3)}=\left(\mathrm{ERR}^{(2)} \omega_{1}^{(?)}-\mathrm{ERR}^{(1)} \omega_{1}^{(1)}\right) /\left(\mathrm{ERR}^{(2)}-\mathrm{ERR}^{(1)}\right)$

Convergence was accepted at the $N$ th iteration if $\mathrm{ERR}^{(N)}<10^{-4} \mathrm{~cm}$. In all the cases analysed $N \leqslant 6$.

Two examples which show the application of this method are presented in Figs 7 and 8. The evolution of shaft friction and total axial load along the pile, with increasing degree of consolidation, is presented in Figs 7 (a) and (b) and 8 (a) 

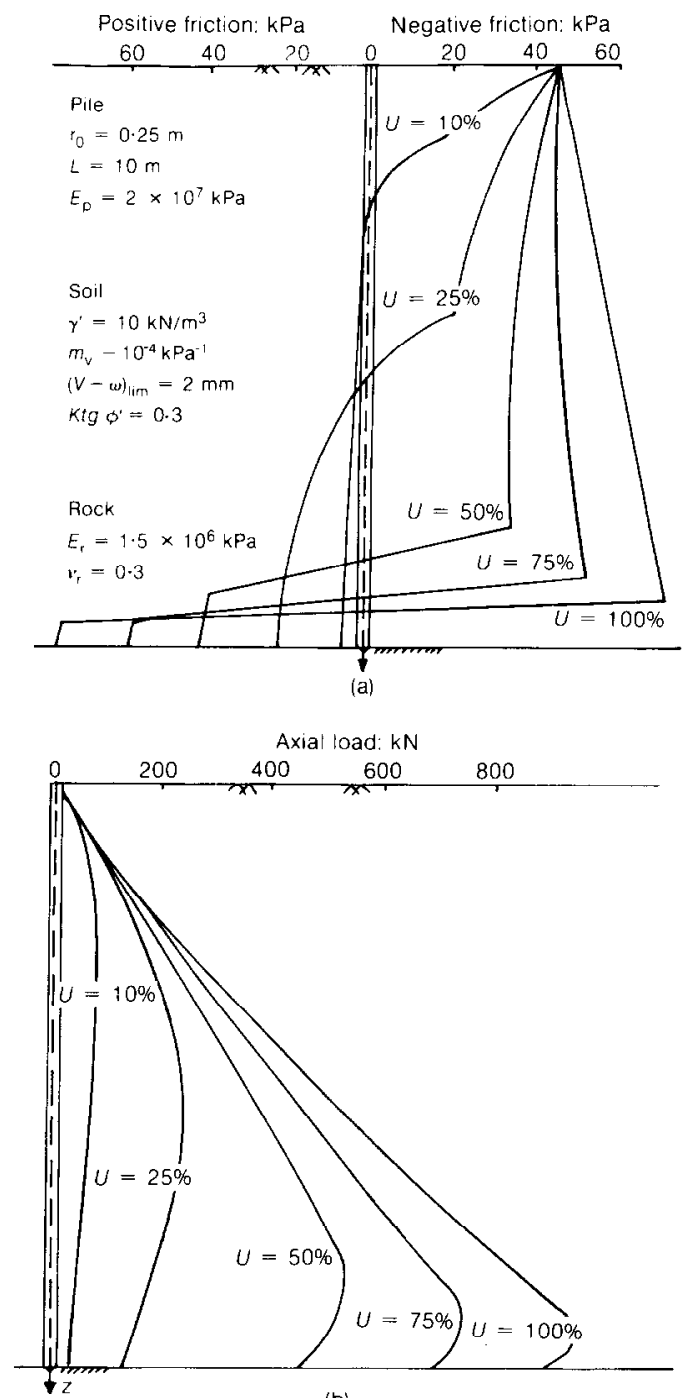

(b)

Fig. 8. Evolution of negative skin friction with degree of consolidation for an end bearing pile; consolidation induced by an external uniform load $\Delta \sigma=150 \mathrm{kPa}$. Impervious soil-pile interface: (a) shear stress distribution along the pile shaft; (b) total downdrag axial forces; (c) stress histories of some points along the shaft

and (b). In both cases a limit shear stress linearly increasing with depth, based on an effective stress proccdure for shear strength evaluation, was adopted. It may be written as

$$
\tau_{1}=\sigma_{\mathrm{h}}{ }^{\prime} \tan \phi^{\prime}=K \tan \phi^{\prime}\left(\gamma^{\prime} z+\Delta \sigma^{\prime}\right)
$$

where $\sigma_{\mathrm{h}}{ }^{\prime}$ is the effective horizontal stress, $K$ the lateral earth pressure, $\tan \phi^{\prime}$ the frictional strength parameter, $\gamma^{\prime}$ the submerged unit
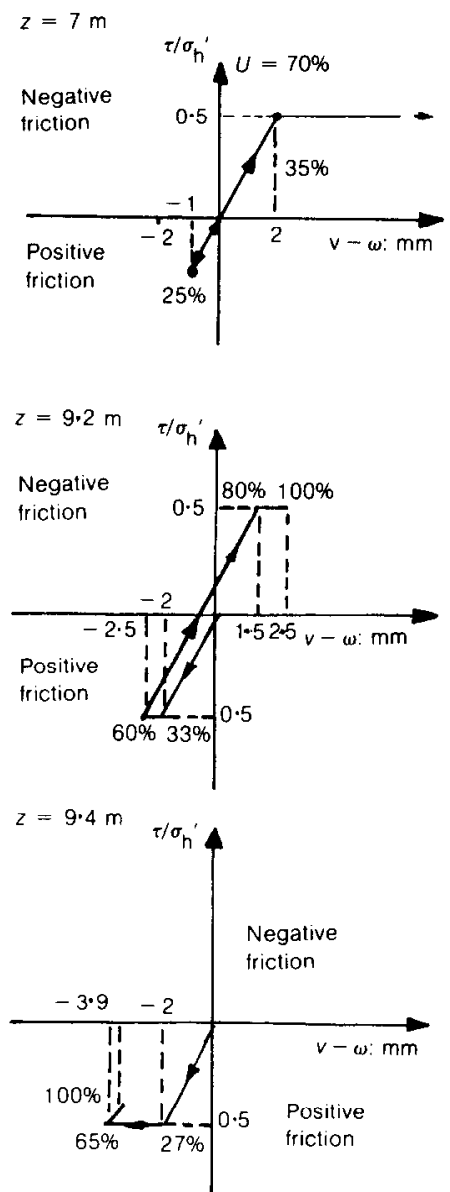

(c)

weight and $\Delta \sigma^{\prime}$ the external load transferred into vertical effective stress. A stress-relative displacement law including recoverable and plastic terms with a constant relative displacement $(v-\omega)_{\mathrm{lim}}=2 \mathrm{~mm}$ was assumed (see Fig. 4). Consolidation of the soil was induced by an externally applied load so that the displacement $v$ is given by equation (8).

In Fig. 7 the pile-soil interface is assumed to be drained as may be the case in a previous pile. $\Delta \sigma^{\prime}$ is then constant and equal to the applied external load. In the more common example (Fig. 8) the pile-soil interface drains at the same speed as the surrounding soil and therefore the vertical effective stress $\Delta \sigma^{\prime}$ increases in time as consolidation proceeds.

In both cascs, for the low range of degrees of consolidation $(U<50 \%)$, a large portion of the pile length is in a state of displacement compatibility. This zone decreases as consolidation 


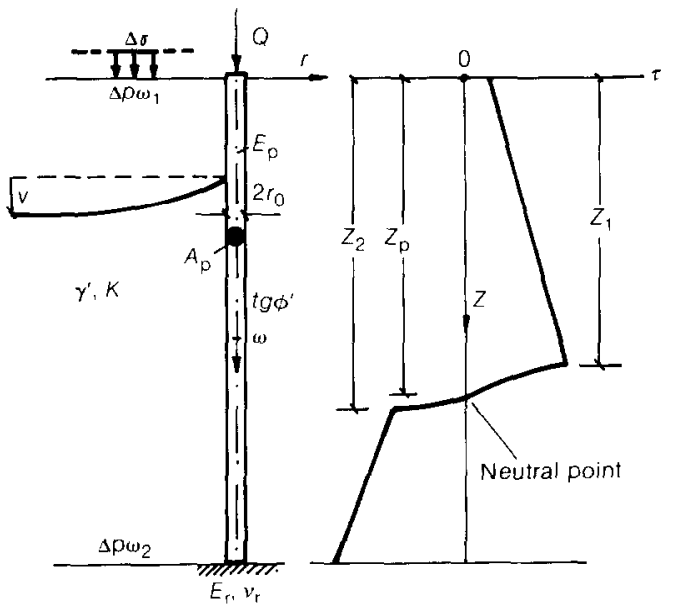

Fig. 9. Definition of symbols: dimensionless formulation

advances and, at the same time, the neutral point tends towards the pile base. For these particular cases the elastic zone is negligible for degrees of consolidation larger than $75 \%$.

An interesting result is the cyclic behaviour experienced, during consolidation, by the shear stress at some of the shaft points (Figs 7(c) and $8(\mathrm{c})$ ).

Any realistic stress transfer function should therefore include the possibility for stress reversals at any time during consolidation.

\section{DIMENSIONLESS FORMULATION}

At this stage it seems convenient to formulate the problem anew in dimensionless terms in order to reach more general conclusions. A simplified bilinear transfer function (Fig. 4) with limiting shear values given by equation (20) will be adopted. Along the pile, a zone of (elastic) displacement compatibility around the neutral point and a pair of plastic zones are distinguished (Fig. 9). The detailed analysis is developed separately in Appendix 1. The solution is expressed in terms of the dimensionless quantities

$$
\begin{aligned}
C_{1}= & K \operatorname{tg} \phi^{\prime} \gamma^{\prime} L^{2} / E_{\mathrm{p}} r_{0} \\
C_{2}= & K \operatorname{tg} \phi^{\prime} \Delta \sigma L / E_{\mathrm{p}} r_{0}=C_{1} \Delta \sigma / \gamma^{\prime} L \\
C_{3}= & (v-\omega)_{\text {lim }} / L \\
C_{4}= & m_{\mathrm{v}} \Delta \sigma \text { if settlement is induced by } \\
& \text { uniform external load } \\
= & \Delta p_{\omega_{2}} m_{\mathrm{v}} \text { if settlement is induced by } \\
& \text { changes in piezometric level } \\
C_{5}= & \left(1-\nu_{\mathrm{r}}^{2}\right) \pi E_{\mathrm{p}} r_{0} / E_{\mathrm{r}} L \\
C_{6}= & Q / A_{\mathrm{p}} E_{\mathrm{p}} \\
C_{7}= & \left(\Delta p_{\omega_{1}}-\Delta p_{\omega_{2}}\right) m_{\mathrm{v}}
\end{aligned}
$$

Repeated application of the developed computing procedure for a wide variety of combina-

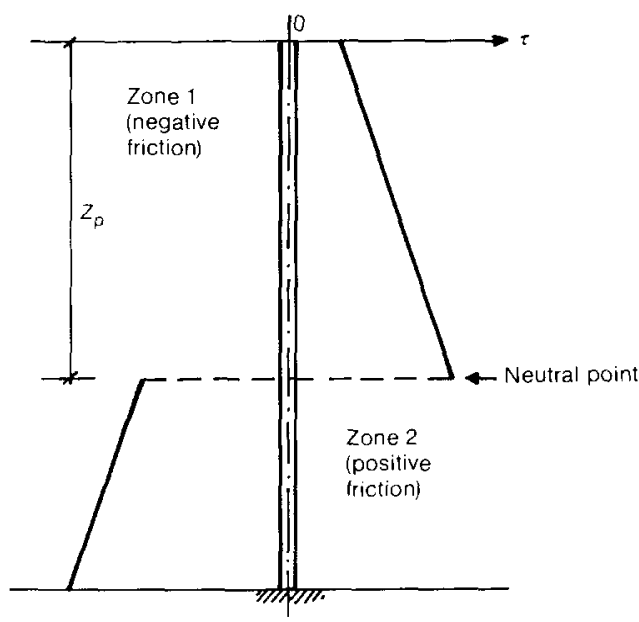

Fig. 10. Distribution of the limiting shear stress along the pile shaft if the thickness of the elastic zone is neglected

tions of the relevant dimensionless factors showed that, at the end of consolidation, the shaft shear stresses had reached their limiting values for most of the pile length. Consistently the elastic zone in which soil-pile deformation compatibility exists was very narrow. In fact for most of the cases analysed this situation was found to be true for a wide range of degrees of consolidation and not only for the final stages. Exceptions to this particular distribution of shear stresses were found either when the end bearing stratum had a high deformability or in cases of relatively high stiffness of the consolidating layer. Both cases are of little practical interest.

If, according to these findings, an elastic zone of zero thickness (neutral point) is assumed (Fig. 10) the solution can be simplified (see Appendix 1). Once the position of the neutral point $Z_{p}=$ $z_{\mathrm{p}} / L$ is known, all the relevant stresses and displacements of the pile are easily computed as follows.

Pile normal stress at the neutral point

$\sigma_{Z=Z_{\mathrm{p}}}=\frac{2 K \operatorname{tg} \phi^{\prime}}{r_{0}}\left(\Delta \sigma L Z_{\mathrm{p}}+1 / 2 \gamma^{\prime} Z_{\mathrm{p}}^{2} L^{2}\right)+Q / A_{\mathrm{p}}$

Pile normal stress at the end bearing point

$$
\begin{aligned}
\sigma_{Z=1}=\frac{2 K \operatorname{tg} \phi^{\prime}}{r_{0}}\left[\Delta \sigma L\left(2 Z_{p}-1\right)+\right. & \left.\gamma^{\prime} L^{2}\left(Z_{\mathrm{p}}^{2}-1 / 2\right)\right] \\
& +Q / A_{p}
\end{aligned}
$$

Displacement at the pile point

$$
\omega_{\mathrm{b}}=\sigma_{Z=1} \pi r_{0}\left(1-\nu_{\mathrm{r}}^{2}\right) / 2 E_{\mathrm{r}}
$$


Displacement at the pile top

$$
\begin{aligned}
\omega_{\mathrm{t}}= & \omega_{\mathrm{b}}+\frac{2 K \operatorname{tg} \phi^{\prime}}{r_{0} E_{\mathrm{p}}}\left[\Delta \sigma L^{2}\left(2 Z_{\mathrm{p}}-Z_{\mathrm{p}}{ }^{2}-1 / 2\right)\right. \\
& \left.+\gamma^{\prime} L^{3}\left(Z_{\mathrm{p}}{ }^{2}-2 / 3 Z_{\mathrm{p}}{ }^{3}-1 / 6\right)\right]+\frac{Q L}{A_{\mathrm{p}} E_{\mathrm{p}}}
\end{aligned}
$$

A limiting case for the applicability of this simplified approach is found when the pile does not transmit any load to the end bearing stratum. Some extreme combination of the dimensionless parameters controlling the problem may lead to this situation or even result in negative stresses. The condition $W(1)=0$ leads to a set of critical positions for the neutral point which are given by

$$
\begin{aligned}
Z_{\mathrm{rc}}= & -C_{2} / C_{1}+\sqrt{ }\left[\left(C_{2} / C_{1}\right)^{2}\right. \\
& \left.+\left(1 / 2+C_{2} / C_{1}-C_{6} / 2 C_{1}\right)\right] \\
= & F\left(C_{2} / C_{1}, C_{6} / C_{1}\right)
\end{aligned}
$$

This relationship is shown in Fig. 11. If there is no external load acting on the pile $\left(C_{6}=0\right)$ the limiting values for the position of the neutral point are in the range $Z_{\mathrm{pc}}=\sqrt{2} / 2$ (when the limiting shear stress increases linearly from a zero value at the surface) to $Z_{\mathrm{pc}}=0.5$ (when uniform shear strength is assumed throughout the pile length). The influence of the external load is always to raise the position of the critical neutral point. Once a value of $Z_{p}$ is found using the hypothesis of fully plastic distribution of shear stresses along the pile, Fig. 11 may be used to obtain an indication of the soundness of the hypothesis. Computed $Z_{\mathrm{p}}$ values close to the values shown in Fig. 11 indicate the need for a more precise analysis along the lines developed previously.

The solution given by equations (21)-(24) is thought to be of some interest for most practical situations. It is simple to use and gives, if compared with the full solution which has to be obtained numerically, almost the same answer.

A number of graphs covering a wide range of dimensionless design parameters are presented in Fig. 12. They give the position of the neutral point in the absence of external load acting on the pile. The critical positions of the neutral point have also been taken into account in drawing these graphs.

The applicability of this procedure is checked later against the results of a number of instrumented case histories.

\section{EXTENSION TO OTHER PRACTICAL CASES}

An interesting feature of the model developed is its adaptability to a variety of situations. In particular it is especially well suited for studying

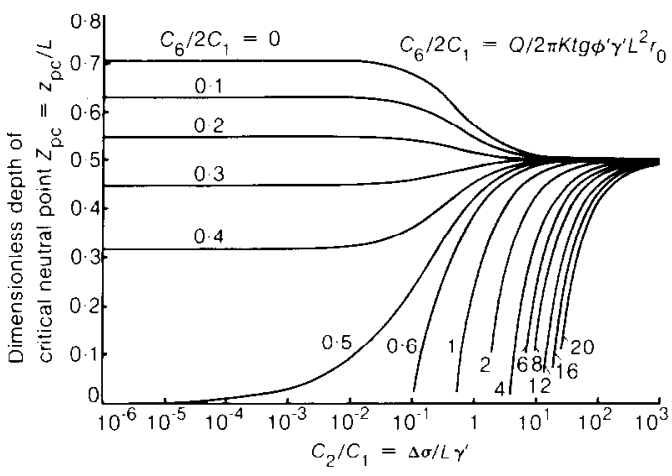

Fig. 11. Limiting values for the position of the neutral point when no load is transferred to the lower bearing stratum

the negative skin friction in non-homogeneous deposits provided that the transfer function for each layer is known and the distribution of consolidation settlements could be computed.

For a general case there is no hope for analytical solutions and resort should be made to numerical solutions. The shooting method is simple and powerful.

A common and interesting case is presented in Fig. 13. A layer of low deformability soil (i.e. a sandy layer, a compacted fill) rests over a consolidating clay layer. For most of the practical cases, at the end of consolidation the thickness of the zone of settlement compatibility is very narrow and may be reduced to a point. With this assumption if the upper layer moves as a rigid body and the shear strength is fully mobilized, a relationship identical to equation (45) (Appendix 1) may be established to find the location of the neutral point. The coefficients $a_{1}$, $a_{2}$ and $a_{3}$ are now given by

$$
\begin{aligned}
a_{1}= & \frac{6}{5 p_{2}{ }^{*} L}\left(\frac{-2 \pi r_{0} p_{2}}{I_{\mathrm{r}}}+\frac{C}{L}+\frac{3 q_{2}{ }^{*}}{2}-p_{2}{ }^{*} L\right) \\
a_{2}= & \frac{6}{5 p_{2}{ }^{*} L^{2}}\left(\frac{-4 \pi r_{0} q_{2}}{I_{\mathrm{r}}}+\frac{Q}{E_{\mathrm{p}} r_{0}{ }^{2}}-2 q_{2}{ }^{*} L+B\right. \\
& \left.-b\left(q_{2}{ }^{*}-q_{1}{ }^{*}\right)-\frac{b^{2}}{2}\left(p_{2}{ }^{*}-p_{1}{ }^{*}\right)\right) \\
a_{3}= & \frac{6}{5 I_{\mathrm{r}} p_{2}{ }^{*} L^{3}}\left[-\pi r_{0} b^{2}\left(p_{1}-p_{2}\right)-2 \pi r_{0} b\left(q_{1}-q_{2}\right)\right. \\
& +\pi r_{0} L^{2} p_{2}+2 \pi r_{0} q_{2} L+\frac{p_{2}{ }^{*} I_{\mathrm{r}} L^{3}}{6}-\frac{O L I_{\mathrm{r}}}{\pi r_{0} E_{\mathrm{p}}}-Q \\
& +\frac{q_{2}{ }^{*} I_{\mathrm{r}} L^{2}}{2}-\frac{b^{2} I_{\mathrm{r}} L}{2}\left(p_{2}{ }^{*}-p_{1}{ }^{*}\right) \\
& \left.-b I_{\mathrm{r}} L\left(q_{2}{ }^{*}-q_{1}{ }^{*}\right)+A L I_{\mathrm{r}}\right]
\end{aligned}
$$



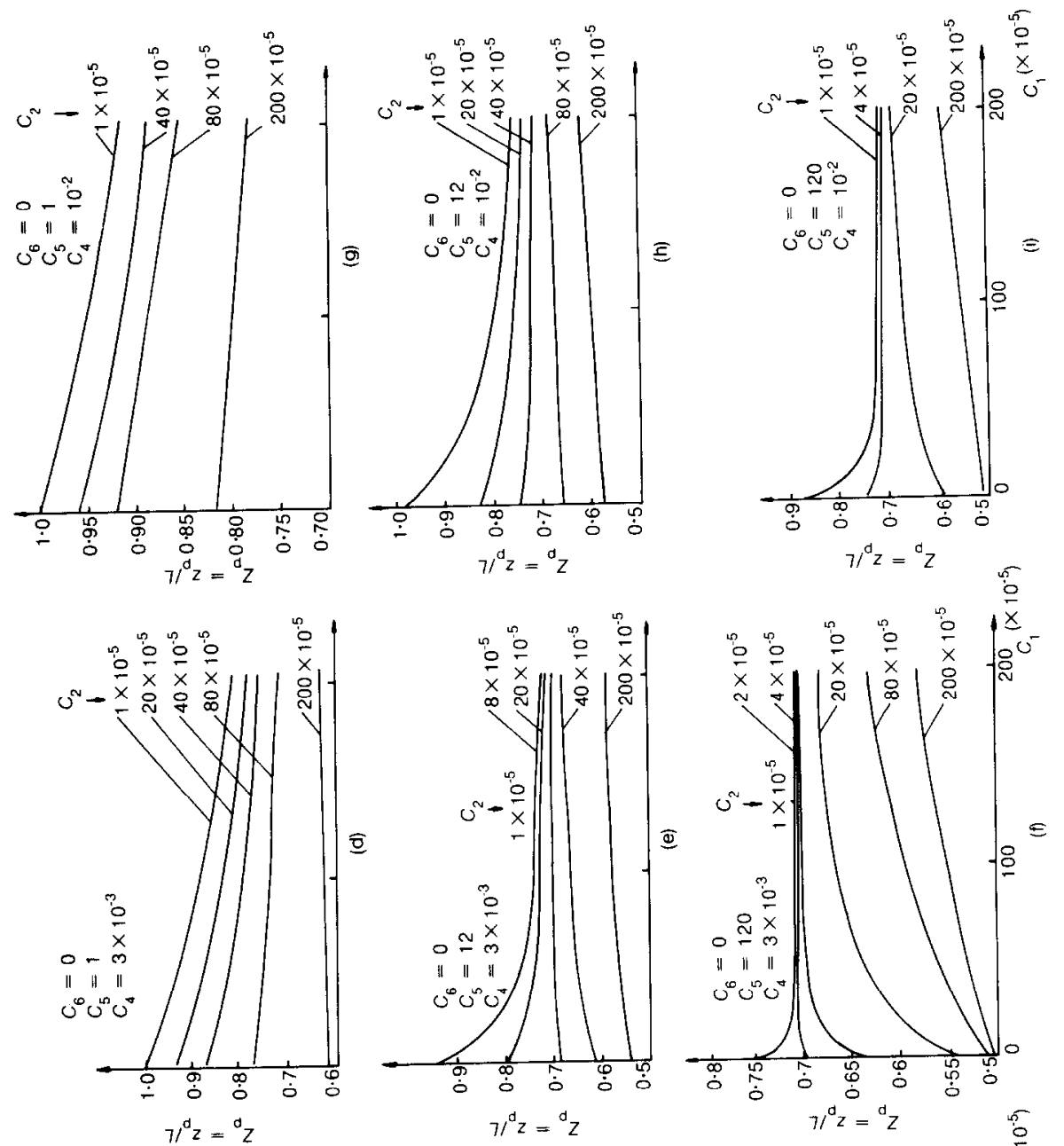

뭉
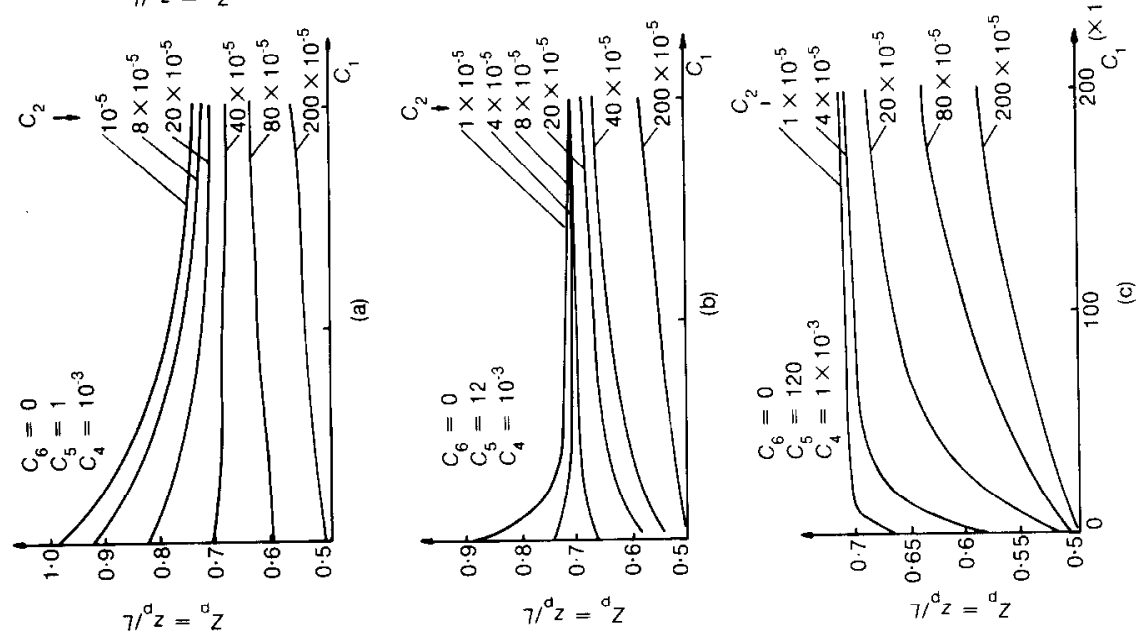


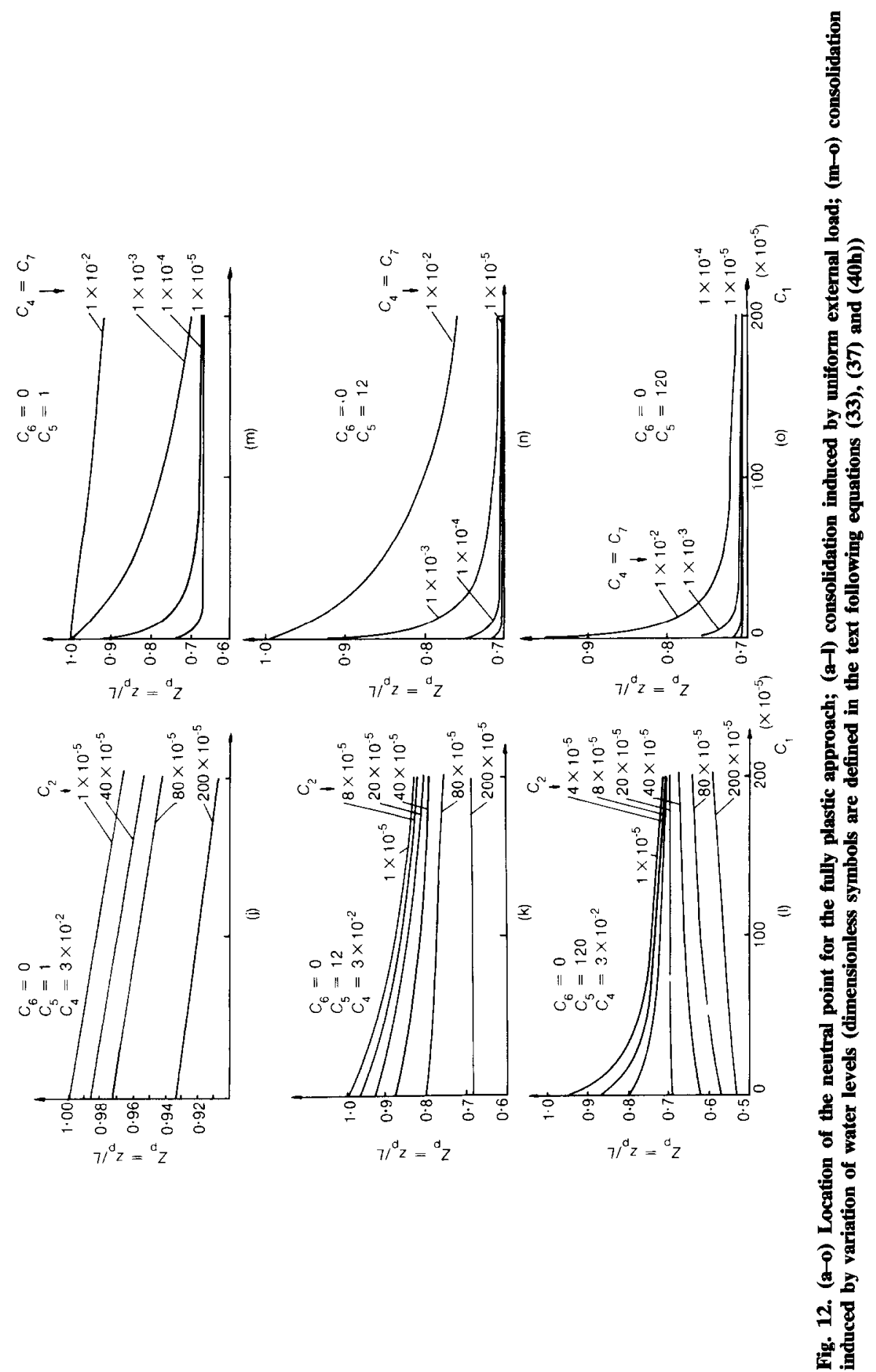




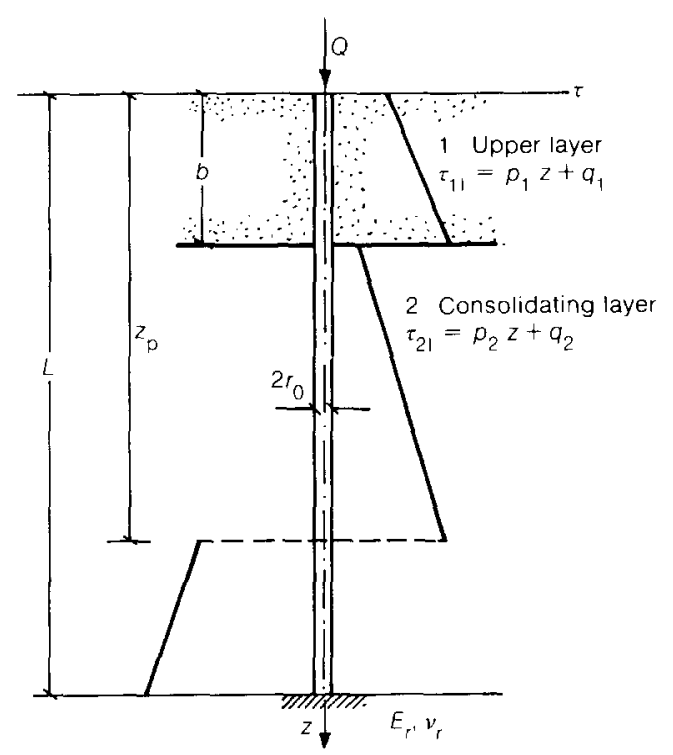

Fig. 13. Non-deformable layer over consolidating stratum. Fully plastic approach

where $p_{1}^{*}=2 p_{1} / r_{0} E_{\mathrm{p}}, \quad q_{1}^{*}=2 q_{1} / r_{0} E_{\mathrm{p}}, \quad p_{2}^{*}=$ $2 p_{2} / r_{0} E_{\mathrm{p}}, \quad q_{2}{ }^{*}=2 q_{2} / r_{0} E_{\mathrm{n}}, \quad V=A+B Z+C Z^{2}$, and $I_{\mathrm{r}}=2 r_{0} E_{\mathrm{r}} /\left(1-\nu_{\mathrm{r}}^{2}\right)$. The symbols not defined previously are indicated in Fig. 13. Once the location of the neutral point is known, the computation of significant stresses and displacements of the pile is straightforward.

The application of load over the pile at any time during the consolidation process is another

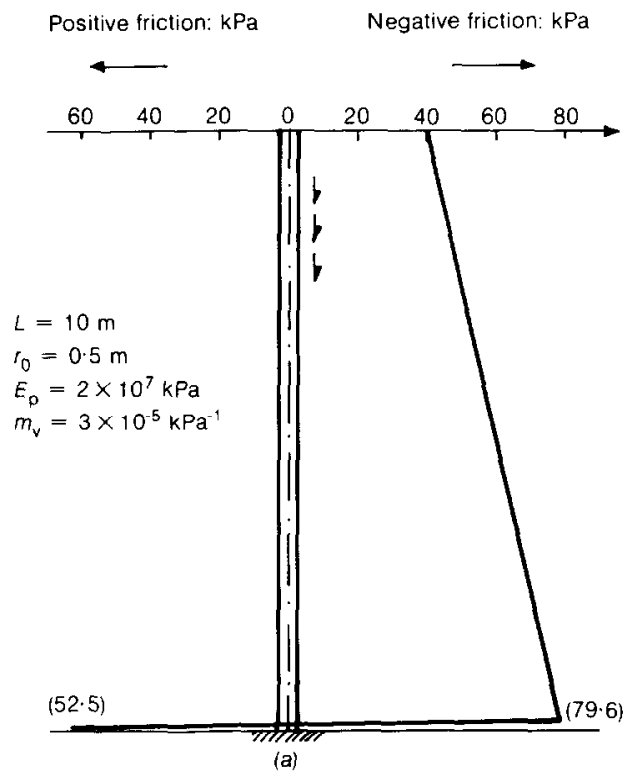

case which can be handled without special difficulties. Repeated stress displacement cycles may result as a consequence of both arbitrary load histories and the consolidation process itself, as indicated before. A simple case is illustrated in Fig. 14. At the end of the consolidation induced by a reduction in water pressure $\left(\Delta p_{\omega_{1}}=\right.$ $\Delta p_{\omega_{2}}=100 \mathrm{KPa}$ ) at both ends of the pile (Fig. $14(\mathrm{a}))$ an external load is applied $\left(\sigma_{Q}=2 \times\right.$ $10^{3} \mathrm{kPa}$ ) (Fig. 14(b)). Since the pile is assumed to rest in an incompressible layer the neutral point in both cases is very close to the pile bottom. For this particular case the application of the load causes a complete reversal of shear stress conditions along the pile shaft.

\section{COMPARISON WITH FIELD MEASUREMENTS}

Several case records in which the negative skin friction on single piles was measured were examined in order to check the preceding fully plastic analysis. Surprisingly, few of them reported the necessary minimum amount of field data to allow the proper application of the developed prediction procedures. In most of the cases the data presented could only be used to perform qualitative comparisons. Only those cases allowing for a quantitative estimation of downdrag loads on the pile and its comparison with the actual measured loads are reviewed here.

An interesting case history was presented by Endo, Minou, Kawasaki \& Shibata (1969). Two vertical end bearing piles, a battered pile and a

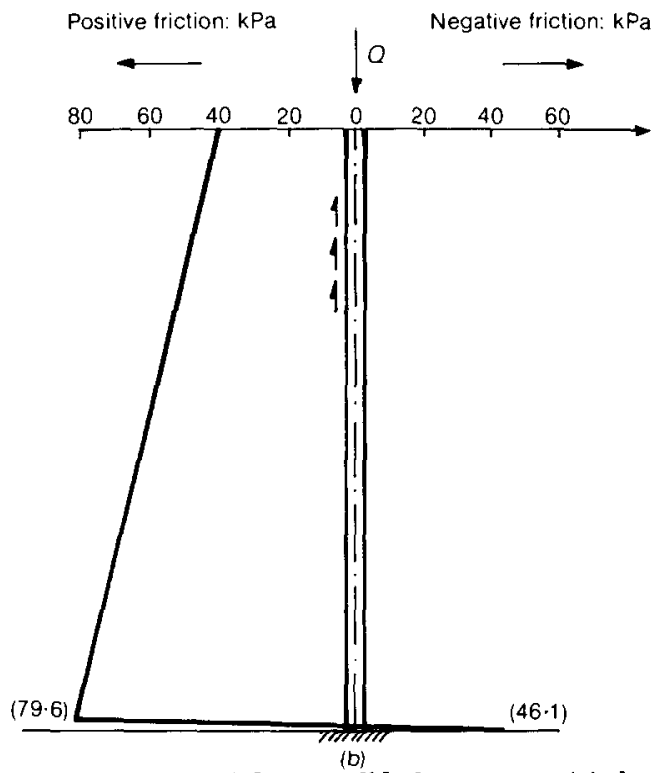

Fig. 14. Effect of the application of an external load on the pile at the end of the consolidation process: (a) shear stress distribution corresponding to the downdrag effect induced by a reduction in water pressures at both ends of the pile; (b) efiect of the application of an external load at the pile top 
Table 1. Significant parameters of the piles analysed

\begin{tabular}{|c|c|c|c|c|c|c|c|c|c|c|}
\hline $\begin{array}{l}\text { Pile } \\
\text { (original } \\
\text { code) }\end{array}$ & $\begin{array}{l}\text { Length: } \\
\mathrm{m}\end{array}$ & $\begin{array}{l}\text { Cross-section } \\
D_{\mathrm{cxl}}=\text { external } \\
\text { diameter } \\
e=\text { thickness }\end{array}$ & $\begin{array}{c}\gamma^{\prime}: \\
\mathrm{kN} / \mathrm{m}^{3}\end{array}$ & $\begin{array}{c}m_{\mathrm{v}}: \\
(\mathbf{k P a})^{-1}\end{array}$ & $\begin{array}{l}E_{\mathrm{r}}: \\
\mathrm{kPa}\end{array}$ & $\begin{array}{l}E_{\mathrm{p}}: \\
\mathrm{kPa}\end{array}$ & $\begin{array}{l}\Delta p_{\omega_{2}}: \\
\mathrm{kPa}\end{array}$ & $\begin{array}{l}\Delta \sigma: \\
\mathrm{kPa}\end{array}$ & $K \operatorname{tg} \phi^{\prime}$ & Reference \\
\hline $\mathrm{cE} 43$ & 43 & $\begin{array}{l}D_{c \text { ct }}=609.6 \mathrm{~mm} \\
e=9.5 \mathrm{~mm}\end{array}$ & 7 & $2.2 \times 10^{-4}$ & $6 \times 10^{4} \div$ & $2 \times 10^{8}$ & 35 & - & $0 \cdot 32$ & \multirow{2}{*}{$\begin{array}{l}\text { Endo et al. } \\
\text { (1969) }\end{array}$} \\
\hline $\mathrm{oE} 43$ & 43 & $\begin{array}{l}D_{\text {cxt }}=609.6 \mathrm{~mm} \\
e=9.5 \mathrm{~mm}\end{array}$ & 7 & $2.2 \times 10^{-4}$ & $6 \times 10^{4}+$ & $2 \times 10^{8}$ & 35 & - & $0 \cdot 2$ & \\
\hline B & 45 & $\begin{array}{l}\text { Area }=164 \mathrm{~cm}^{2} \\
\text { Perimeter }=164 \mathrm{~cm}\end{array}$ & 9 & $2.5 \times 10^{-4}$ & $8 \times 10^{4}$ & $2 \times 10^{8}$ & - & 114 & $0 \cdot 2$ & $\begin{array}{l}\text { Johannessen \& } \\
\text { Bjerrum } \\
\text { (1965) }\end{array}$ \\
\hline$A^{*}$ & 21 & $\begin{array}{l}D_{\text {ext }}=300 \mathrm{~mm} \\
e=7 \mathrm{~mm}\end{array}$ & 9 & $2.5 \times 10^{-4}$ & $10^{5}$ & $2 \times 10^{8}$ & - & 114 & $0 \cdot 25$ & \multirow{4}{*}{$\begin{array}{l}\text { Bjerrum et al. } \\
(1969)\end{array}$} \\
\hline $\mathrm{C}^{*}$ & 40 & $\begin{array}{l}D_{\text {ext }}=500 \mathrm{~mm} \\
e=8 \mathrm{~mm}\end{array}$ & 9 & $2.5 \times 10^{-4}$ & $2.4 \times 10^{5}$ & $2 \times 10^{8}$ & - & 140 & $0 \cdot 18$ & \\
\hline $\mathrm{G}^{*}$ & 30 & $\begin{array}{l}D_{\text {ext }}=500 \mathrm{~mm} \\
e=8 \mathrm{~mm}\end{array}$ & 9 & $2.5 \times 10^{-4}$ & $2.4 \times 10^{5}$ & $2 \times 10^{8}$ & - & 100 & $0 \cdot 18$ & \\
\hline $\mathbf{H}^{*}$ & 33 & $\begin{array}{l}D_{e x t}=500 \mathrm{~mm} \\
e=8 \mathrm{~mm}\end{array}$ & 9 & $2.5 \times 10^{-4}$ & $2.4 \times 10^{5}$ & $2 \times 10^{8}$ & - & 100 & $0 \cdot 18$ & \\
\hline
\end{tabular}

* An upper $9 \mathrm{~m}$ thick fill layer was accounted for by means of an external load on the pile which is given in the reference. These loads were $1,5,3 \cdot 5$ and $3 \cdot 5 \times 10^{5} \mathrm{~N}$ for piles $\mathrm{A}, \mathrm{C}, \mathrm{G}$ and $\mathrm{H}$ respectively.

† Estimated from SPT records.

floating pile were installed in a $43 \mathrm{~m}$ thick alluvium underlain by sand. Only the first two cases could be analysed by the developed approach. Negative skin friction loads were induced by a decrease in the piezometric head of the lower sand stratum. The relevant pile and soil parameters are indicated in Table 1 . The deformation modulus of the lower sand was not directly reported. Only SPT $N$ values are available. The published records show a rapid increase in the penetration resistance that reaches values of $N=50-60$ at 3-4 m below the contact with the consolidated alluvium. In order to estimate the amount of porewater pressure reduction in the lower sand, the measured surface settlement with time was interpreted according to the onedimensional consolidation theory. An average value of $3.5 \mathrm{~m}$ of piezometric head variation was computed. A set of dimensionless parameters were found (Table 2) and maximum and point

Table 2. Dimensionless parameters and loads computed and recorded in the piles indicated

\begin{tabular}{|c|c|c|c|c|c|c|c|c|c|}
\hline \multirow{2}{*}{$\begin{array}{l}\text { Pile } \\
\text { (original } \\
\text { code) }\end{array}$} & \multicolumn{5}{|c|}{ Dimensionless coefficients } & \multicolumn{2}{|c|}{$\begin{array}{l}\text { Maximum load: } \mathrm{kN} \\
\text { (neutral point) }\end{array}$} & \multicolumn{2}{|c|}{ Point load: $k N$} \\
\hline & $C_{1}$ & $C_{2}$ & $C_{4}$ & $C_{5}$ & $C_{6}$ & Predicted & Measured & Predicted & Measured \\
\hline $\mathrm{cE} 43$ & $1.1 \times 10^{-3}$ & - & $7 \cdot 7 \times 10^{-3}$ & $4 \cdot 2$ & $0 \cdot 0$ & 2820 & 3020 & 1735 & 1490 \\
\hline oE 43 & $6.8 \times 10^{-4}$ & - & $7.7 \times 10^{-3}$ & $4 \cdot 2$ & $0 \cdot 0$ & 1840 & 1760 & 1253 & 710 \\
\hline B & $9.0 \times 10^{-4}$ & $2.5 \times 10^{-4}$ & $2.9 \times 10^{-2}$ & $3 \cdot 2$ & - & - & - & 3430 & 3280 \\
\hline A & $3.5 \times 10^{-4}$ & $2 \cdot 1 \times 10^{-4}$ & $2.9 \times 10^{-2}$ & $3 \cdot 8$ & $7 \cdot 5 \times 10^{-5}$ & 1050 & 1200 & 970 & 660 \\
\hline $\mathrm{C}$ & $8.1 \times 10^{-4}$ & $3.1 \times 10^{-4}$ & $3.5 \times 10^{-2}$ & $0 \cdot 9$ & $2 \cdot 0 \times 10^{-4}$ & 3990 & 2930 & 3865 & 2930 \\
\hline $\mathrm{G}$ & $4.6 \times 10^{-4}$ & $1.7 \times 10^{-4}$ & $2.5 \times 10^{-2}$ & $1 \cdot 3$ & $1.4 \times 10^{-4}$ & 2270 & 2900 & - & - \\
\hline $\mathbf{H}$ & $5.5 \times 10^{-4}$ & $1.9 \times 10^{-4}$ & $2.5 \times 10^{-2}$ & $1-2$ & $1.4 \times 10^{-4}$ & 2540 & 2100 & - & - \\
\hline
\end{tabular}




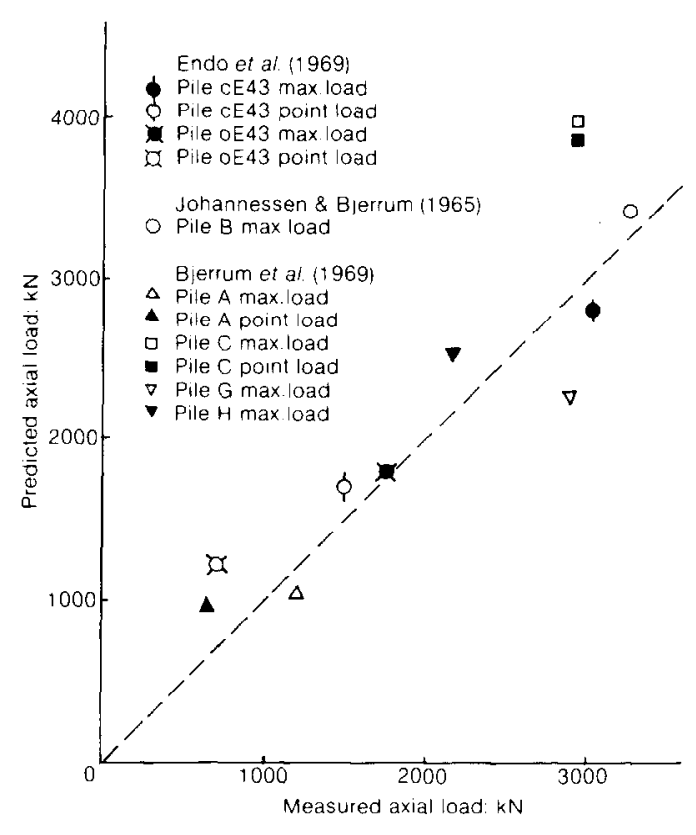

Fig. 15. Summary of comparisons between predicted and measured downdrag loads

loads predicted. They are compared in Table 2 with the measured values.

Johannessen \& Bjerrum (1965) describe measurements on a steel pile driven to rock through $45 \mathrm{~m}$ of soft to medium glacial clay subjected on its surface to a uniform loading induced by $10 \mathrm{~m}$ of fill. The reported consolidation settlement $(1.2 \mathrm{~m})$ of the surface provides an average estimation of the cocfficicnt $m_{\mathrm{v}}$. No direct indication of the deformation characteristics of the underlying bedrock (Ordovician calcareous schist) was given. However, the reported settlement of the pile point $(6 \mathrm{~cm})$ when the point load reached 250 tons was used to derive an equivalent rock modulus $E_{\mathrm{r}}$. The remaining pile and soil parameters, dimensionless coefficients and predicted and measured loads are indicated in Tables 1 and 2 . The friction within the fill layer was observed to be relatively small. It has been disregarded in this evaluation.

A number of isolated piles subjected to negative friction under different conditions were analysed by Bjerrum, Johannessen \& Eide (1969). Several piles were installed to evaluate the performance of shear stress reduction procedures. No estimation of the shear transfer constants was given for these cases. Accordingly only the reference piles have been analysed. For all the cases the observations started and ended in a fraction of the total consolidation period. However, the current rate of settlement during the observation period coupled with the small shear strain necessary to mobilize the interface strength should make this approach represent quite closely the actual stress conditions of the piles. Some discrepancies in the additional effective stress conditions induced hy the fill should arise, however. Their influence is judged to be of lesser importance. In any case the predicted values should be an upper bound of (but it is hoped close to) the measured ones.

The so-called pile $\mathrm{A}$ was driven to bedrock through $9 \mathrm{~m}$ of upper fill and a layer of $21 \mathrm{~m}$ of consolidating clayey silt. The influence of the fill layer was taken into account by means of an external load of $10^{5} \mathrm{~N}$ according to the data given in the paper. Only indirect data (water content, undrained shear strength) of the silty clay could be used to estimate the deformability of the soil. However, the similarity to the soil conditions reported in the previously analysed case (Johannessen \& Bjerrum, 1965) prompted us to adopt similar values for $m_{\mathrm{v}}$. The point settlement was used to derive an equivalent rock modulus. Similar estimations were made for another site (pile ()) where a tubular pile was installed through $15 \mathrm{~m}$ of fill and $40 \mathrm{~m}$ of marine clay. The fill exerted in this case a measured load of $5 \times 10^{5} \mathrm{~N}$ on the pile at the level of the fill-clay contact. The remaining soil and pile parameters and the computed and measured loads for both piles are presented in Tables 1 and 2.

Two more piles (piles $\mathrm{G}$ and $\mathrm{H}$ ) were installed in a nearby area where a fill of $13 \mathrm{~m}$ had been in place for 70 years, and the rates of settlement were very low compared with those for the preceding two cases. The fill transmitted a uniform load of $10 \mathrm{kPa}$. The pile-fill friction was substituted by a concentrated loading of $3 \cdot 5 \times$ $10^{5} \mathrm{~N}$ at the upper clay level according to measurements. Soil conditions were taken as in the pile $\mathrm{C}$ case. The computed loads are shown in Table 2. The measured values after two years of observation are also indicated.

A summary of the observed and predicted loads is plotted in Fig. 15. Most of the predicted downdrag loads tend to be somewhat larger than the measured values. This is not surprising in view of the fact that a fully plastic approach has been used as a prediction theory, coupled with the fact that some observations did not last for the full consolidation period. Despite these effects the agreement is quite satisfactory.

\section{CONCLUSIONS}

This Paper develops a simple and accurate model of the load transfer induced by negative skin friction. The resulting equations have been 
formulated in dimensionless terms and a versatile numerical solution procedure has been devised. In this way fairly general analyses for arbitrary soil profiles, consolidation conditions and load histories can be performed at a limited cost and effort. Sensitivity analyses are specially facilitated by this approach.

Some interesting features of the shear transfer conditions at the soil-pile interface have also been clarified. It was shown that even the simplest cases involve, at the local level, stress reversals.

It has also been shown that for many practical cases the distribution of shear stresses along the shaft can be simplified further so that the length of strain compatibility between soil and pile could be reduced to a single point. In this way closed form solutions for all the relevant design parameters were derived.

The charts may be used in many practical situations. A few well-documented case records were examined by means of the developed procedures. The comparison with the measured response of the piles, in terms of downdrag forces, was quite satisfactory.

\section{ACKNOWLEDGEMENTS}

The work described in this Paper is a part of a more general analysis of negative skin friction carried out within the Geotechnical Department of the Polytechnic University of Barcelona. Only the most practical solutions have been included in the Paper. The Authors gratefully acknowledge the work carried out by other members of the group in charge of the project, namely the civil engineers $\mathrm{Mr}$ I. Duque and $\mathrm{Mr}$ J. $\mathbf{M}$. Estradé. The work of the second and third Authors of the Paper was financed by grants from the Ministry of Education. Most of the computations were carried out at the Computer Centre of the University.

\section{REFERENCES}

Begemann, H. K. S. P. (1969). Negative skin friction of a single pile, Proc. Special Session Negative Skin Friction Settling Piled Fnds, 7th Int. Conf. Soil Mech., Mexico, Paper 1.

Bjerrum, L., Johannessen, I. J. \& Eide, O. (1969). Reduction of negative skin friction on steel piles to rock. Proc. 7th Int. Conf. Soil Mech., Mexico 2, 27-33.

Boulon, M., Desrues, J. \& Foray, P. (1978). Calcul des pieux: tassements sous charge de service, frottement négatif. Rev. Française Géotechnique, No. 5, 13-21.

Broms, B. (1977). Negative skin friction. Proc. 6th Asian Reg. Conf. Soil Mech., Singapore 2, 1-75.

Butterfield, R. \& Banerjee, P. K. (1970). A note on the problem of a pile-reinforced half space. Géotechnique 20, No. 1, 100-103.
Chandler, R. J. \& Martins, J. P. (1982). An experimental study of skin friction around piles in clay. Géotechnique 32, No. 2, 119-132.

Clemence, S. P. \& Brumund, W. F. (1975). Largescale model test of drilled pier in sand. J. Geotech. Engng Div. Am. Soc. Civ. Engrs 101, GT 6, 537550 .

Coyle, H. M. \& Reese, L. C. (1966). Load transfer for axially loaded piles in clay. J. Soil Mech. Fdns. Div. Am. Soc. Civ. Engrs 92, SM 2, 1-26.

Elmasry, M. A. (1963). The negative skin friction of bearing piles. Thesis, Swiss Federal Institute of Technology, Zürich.

Endo, M., Minou, ^., Kawasaki, T. \& Shibata, T. (1969). Negative skin friction acting on steel pipe in clay. Proc. 7th Int. Conf. Soil Mech., Mexico 2, 85-92.

Frank, R. (1975). Etude teorique du comportement des pieux sous charge verticale. Introduction de la dilatance. Rapport de Recherche No. 46. Paris: Laboratoire Central des Ponts et Chaussèes.

Johannessen, I. J. \& Bjerrum, L. (1965). Measurement of the compression of a steel pile to rock due to settlement of the surrounding clay. Proc. 6th Int. Conf. Soil Mech., Montreal 2, 261-264.

Kezdi, A. (1960). Contributions to the bearing capacity of piles. Acta Tech. Acad. Sci. Hung. 29, 3-4.

Littlejohn, I. (1976). An experimental study of the adhesion between clay and steel. $J$. Terramech. 13, No. 3, 141-152.

Lupini, J. F., Skinner, A. E. \& Vaughan, P. R. (1981). The drained residual strength of cohesive soils. Géotechnique 31, No. 2, 181-213.

Mitchell, J. K. (1976). Fundamentals of soil behaviour. New York: Wiley.

Poulos, H. G. \& Davis, E. H. (1972). The development of negative friction with time in end-bearing piles. Aust. Geomech. J. C2, No. 1, 11-20.

Poulos, H. G. \& Davis, E. H. (1975). Prediction of downdrag forces in end-bearing piles. $J$. Geotech. Engng Div. Am. Soc. Civ. Engrs 101, GT 2, 189 204.

Randolph, M. F. \& Wroth, C. P. (1978). Analysis of deformation of vertically loaded piles. J. Geotech. Engng Div. Am. Soc. Civ. Engrs 104, GT 12, 1465-1488.

Reese, L. C. (1964). Load versus settlement for an axially loaded pile. Proc. Symp. Bearing Capacity of Piles, Part 2. Roorke, India: Central Building Research Institute.

Reese, L. C., Hudson, W. R. \& Vijayvergiya, V. N. (1969). An investigation of the interaction between bored piles and soil. Proc. 7th Int. Conf. Soil Mech., Mexico 2, 211-216.

Salas, J. A. J. \& Belzunce, J. A. (1965). Resolution teorique de la distribution des forces dans des pieux. Proc. 6th Int. Conf. Soil Mech., Montreal 6, 309-313.

Seed, H. B. \& Reese, L. C. (1957). The action of soft clay along friction piles. Trans. Am. Soc. Civ. Engrs 122, 731-754.

Terzaghi, K. \& Peck, R. B. (1948). Soil mechanics in engineering practice. New York: Wiley.

Terzaghi, K. \& Peck, R. B. (1967). Soil mechanics in engineering practice, 2nd Edn. New York: Wiley. 
Verruijt, A. (1969). A simplified elastic method for the calculation of negative skin friction on piles. Proc. Special Session Negative Skin Friction Settling Piled Fnds, 7th Int. Conf. Soil Mech., Mexico, Paper 5.

Walker, L. K. \& Darvall, P. L. P. (1973). Dragdown on coated and uncoated piles. Proc. 8th Int. Conf. Soil Mech., Moscow 2, Part 1, 257-262.

\section{APPENDIX 1}

From equation (1), valid anywhere along the pile, and assuming a cylindrical shape

$$
-E_{\mathrm{p}} \frac{\mathrm{d}^{2} \omega}{\mathrm{d} z^{2}}=\frac{\Gamma_{\mathrm{p}}}{A_{\mathrm{p}}} \tau=2 \frac{\tau}{r_{0}}
$$

In the following equations dimensionless parameters will be denoted by capital letters $C_{i}$.

\section{Elastic zones}

Shear stresses are linearly related to effective horizontal stress and to relative displacement (Fig. 4)

$$
\tau / \sigma_{\mathrm{h}}{ }^{\prime}=\alpha_{1}(v-\omega)=\frac{\tau_{1}}{\sigma_{\mathrm{h}}{ }^{\prime}} \frac{v-\omega}{(v-\omega)_{\lim }}=\operatorname{tg} \phi^{\prime} \frac{(v-\omega)}{(v-\omega)_{\lim }}
$$

Substituting in (27) and knowing that $\sigma_{\mathrm{h}}{ }^{\prime}=$ $K\left(\gamma^{\prime} z+\Delta \sigma^{\prime}\right)$ results in

$$
-E_{\mathrm{p}} \frac{\mathrm{d}^{2} \omega}{\mathrm{d} z^{2}}=\frac{2}{r_{0}} \frac{K\left(\gamma^{\prime} z+\Delta \sigma^{\prime}\right) \operatorname{tg} \phi^{\prime}}{(v-\omega)_{\lim }}(v-\omega)
$$

Defining the dimensionless variables $Z=z / L, W=$ $\omega / L, V=v / L$, equation (29) becomes

$$
\begin{aligned}
-\frac{\mathrm{d}^{2} W}{\mathrm{~d} Z^{2}}= & \frac{2 L^{2}}{E_{\mathrm{p}} r_{0}}\left[\frac{K \gamma^{\prime} L \operatorname{tg} \phi^{\prime}}{(v-\omega)_{\lim }}\right](V-W) Z \\
& +\frac{2 L^{2}}{E_{\mathrm{p}} r_{0}}\left[\frac{K \Delta \sigma^{\prime} \operatorname{tg} \phi^{\prime}}{(v-\omega)_{\lim }}\right](V-W)
\end{aligned}
$$

The vertical effective stress $\Delta \sigma^{\prime}$ induced by the external load $\Delta \sigma$ should be expressed as

$$
\Delta \sigma^{\prime}=\Delta \sigma-u(Z, T)=\Delta \sigma[1-\Omega(Z, T)]
$$

where $u(Z, T)$ is the excess porewater pressure and $\Omega(Z, T)$ is given by the theory of consolidation. For one-dimensional conditions

$$
\begin{aligned}
\Omega(Z, T) & =\sum_{n=0}^{\infty} \frac{4}{(2 n+1) \pi} \\
& \times \exp \left(-\frac{\pi^{2}(2 n+1)^{2}}{4} T\right) \sin \left(\frac{2 n+1}{2} \pi Z\right)
\end{aligned}
$$

On account of equation (31), equation (30) becomes after some transformations

$$
-\frac{\mathrm{d}^{2} W}{\mathrm{~d} Z^{2}}=2\left\{\frac{C_{1}}{C_{3}} Z+\frac{C_{2}}{C_{3}}[1-\Omega(Z, T)]\right\}(V-W)
$$

where $C_{1}=K \operatorname{tg} \phi^{\prime} \gamma^{\prime} L^{2} / E_{\mathrm{p}} r_{0}, C_{2}=K \operatorname{tg} \phi^{\prime} \Delta \sigma L / E_{\mathrm{p}} r_{0}$ and $C_{3}=(v-\omega)_{\text {lim }} / L$.

The dimensionless consolidation settlement due to external load is

$$
\begin{aligned}
V= & C_{4}\left\{1-Z-\sum_{m=0}^{\infty} \frac{8}{\pi^{2}(2 m+1)^{2}}\right. \\
& \left.\times \exp \left[-\frac{\pi^{2}(2 m+1)}{4} C_{8}\right] \cos \left[\frac{(2 m+1) \pi}{2} Z\right]\right\}
\end{aligned}
$$

Final displacements are given by

$$
V=C_{4}(1-Z)
$$

If settlements are induced by piezometric level changes at both ends of the pile

$$
\begin{aligned}
& V=\left\{\frac{2 C_{4}+C_{7}}{2}-\left(C_{4}+C_{7}\right) Z+\frac{C_{7}}{2} Z^{2}-\frac{2 C_{4}+C_{7}}{2}\right. \\
& \times\left[\sum_{m=0}^{\infty} \frac{1+\frac{C_{4}}{C_{4}+C_{7}}(-1)^{m+1}}{1+\frac{C_{4}}{C_{4}+C_{7}}} \frac{8}{\pi^{2} m^{2}}\right. \\
&\left.\times \exp \left(\frac{-\pi^{2} m^{2} T}{4}\right)(1-\cos (m \pi(1-Z))]\right\}
\end{aligned}
$$

and the final settlement

$$
V=\frac{2 C_{4}+C_{7}}{2}-\left(C_{4}+C_{7}\right) Z+\frac{C_{7}}{2} Z^{2}
$$

In these equations $C_{4}=m_{\mathrm{v}} \Delta \sigma$ if settlement is induced by uniform external load or $C_{4}=\Delta p_{\omega_{2}} m_{\mathrm{v}}$ if settlement is induced by changes in piezometric level, and $C_{7}=\left(\Delta p_{\omega_{1}}-\Delta p_{\omega_{2}}\right) m_{\mathrm{v}}$.

\section{Plastic zones}

Equation (27) becomes

$$
-E_{\mathrm{p}} \frac{\mathrm{d}^{2} \omega}{\mathrm{d} z^{2}}=2 \frac{\tau_{1}}{r_{0}}=2 \frac{\sigma_{\mathrm{h}}{ }^{\prime} \operatorname{tg} \phi^{\prime}}{r_{0}}=\frac{2}{r_{0}} \operatorname{tg} \phi^{\prime}\left(\Delta \sigma+\gamma^{\prime} z-u\right)
$$

Using the dimensionless variables and coefficients just defined

$$
-\frac{\mathrm{d}^{2} W}{\mathrm{~d} Z^{2}}=2\left\{C_{2}[1-\Omega(Z, T)]+C_{1} Z\right\}
$$

Boundary conditions

$$
\begin{aligned}
& Z=0 ; \quad \frac{\mathrm{d} W}{\mathrm{~d} Z}=-C_{6} \\
& Z=z_{1} / L=Z_{1} ; \quad W_{\text {elastic }}=W_{\text {plastic }} \\
& Z=Z_{1} ; \quad\left(\frac{\mathrm{d} W}{\mathrm{~d} Z}\right)_{\text {elastic }}=\left(\frac{\mathrm{d} W}{\mathrm{~d} Z}\right)_{\text {plastic }} \\
& Z=Z_{1} ; \quad 2\left[C_{1} Z+C_{2}\right]=2 C_{3}(V-W) \\
& Z=z_{2} / L=Z_{2} ; \quad W_{\text {plastic }}=W_{\text {elastic }} \\
& Z=Z_{2} ; \quad\left(\frac{\mathrm{d} W}{\mathrm{~d} Z}\right)_{\text {plastic }}=\left(\frac{\mathrm{d} W}{\mathrm{~d} Z}\right)_{\text {elastic }} \\
& Z=Z_{2} ; \quad 2\left[C_{1} Z+C_{2}\right]=2 C_{3}(V-W) \\
& Z=1 ; \quad C_{5}\left[\int_{0}^{Z_{1}}\left(C_{1} Z+C_{2}\right) \mathrm{d} Z+\int_{Z_{1}}^{Z_{2}} 2 C_{3}(V-W) \mathrm{d} Z\right. \\
&\left.+\int_{Z_{2}}^{1}-\left(C_{1} Z+C_{2}\right) \mathrm{d} Z\right]=W(1)
\end{aligned}
$$

where $C_{5}=\left(1-\nu_{\mathrm{r}}^{2}\right) \pi E_{\mathrm{p}} r_{0} / E_{\mathrm{r}} L$ and $C_{6}=Q / A_{\mathrm{p}} E_{\mathrm{p}}$. 
Boundary conditions can also be formulated for stratified soils. For the $j$ th contact between two adjacent layers $j-1$ and $j$, it can be written as

$$
\begin{array}{ll}
Z=z_{\mathrm{j}} / L ; & W_{\mathrm{i}}=W_{\mathrm{j}-1} \\
Z=z_{\mathrm{j}} / L ; & \frac{\mathrm{d} W_{\mathrm{j}}}{\mathrm{d} Z}=\frac{\mathrm{d} W_{\mathrm{j}-1}}{\mathrm{~d} Z}
\end{array}
$$

A family of dimensionless constants $C_{1}, C_{2}$ and $C_{3}$ are correspondingly defined as follows

$$
\begin{aligned}
& C_{1 i}=K_{i} \operatorname{tg} \phi_{i}{ }^{\prime} \gamma_{i}{ }^{\prime} L^{2} / E_{\mathrm{p}} r_{0} \\
& C_{2 i}=K_{\mathrm{i}} \operatorname{tg} \phi_{\mathrm{i}}{ }^{\prime} \Delta \sigma L / E_{\mathrm{p}} r_{0} \\
& C_{3 i}=(v \cdots \omega)_{\lim i} / L
\end{aligned}
$$

Non-circular cross-sections can be accommodated by substituting $r_{0}$ by twice the cross-sectional area/perimeter.

\section{Simplified plastic approach at the end of consolidation}

If an elastic zone of zero thickness (neutral point) is assumed (Fig. 10) the solution can be simplified. The differential equations expressing equilibrium of the pile shaft in the two plastic zones, negative and positive, are written, for the end of consolidation conditions (equation (39) with $\Omega=0$ )

$$
-\frac{\mathrm{d}^{2} W_{j}}{\mathrm{~d} Z^{2}}=2\left(C_{1} Z+C_{2}\right)(-1)^{\mathrm{j}+1} \quad j=1,2
$$

However, the boundary conditions are now

$$
\begin{array}{ll}
Z=0 ; & \frac{\mathrm{d} W_{1}}{\mathrm{~d} Z}=-C_{6} \\
Z=z_{\mathrm{p}} / L ; \quad W_{1}=W_{2} & \mathrm{~d} W_{1} \\
Z=z_{\mathrm{p}} / L ; & \frac{\mathrm{d} W_{2}}{\mathrm{~d} Z} \\
Z=z_{\mathrm{p}} / L ; \quad W_{1}=V & C_{5}\left[\int_{0}^{z_{\mathrm{p}} / L}\left(C_{1} Z+C_{2}\right) \mathrm{d} Z\right. \\
\left.Z=1 ; \quad-\int_{7_{\mathrm{p}} / \mathrm{r}}^{1}\left(C_{1} Z+C_{2}\right) \mathrm{d} Z\right]=W_{2}(1)
\end{array}
$$

The hypothesis of zero thickness of the elastic zone does not imply neglect of its existence. Pile soil displacement compatibility is enforced at the point of shear stress turning from ncgative to positive values.

For a parabolic variation of the free soil settlement $V$ (which includes the common cases of uniform surface load, pore pressure variation at both ends or a combination of both)

$$
V=A+B Z+C Z^{2}
$$

closed form solutions can be found for the problem. In equation (44) consolidation induced by a uniform external load is obtained if $A=C_{4} ; B=-C_{4} ; C=0$. If settlement is induced by change in piezometric conditions $A=\left(2 C_{4}+C_{7}\right) / 2 ; B=-\left(C_{4}+C_{7}\right) ; C=C_{7} / 2$.

A convenient solution is found in terms of the dimensionless depth $Z_{\mathrm{p}}=z_{\mathrm{p}} / L$ of the neutral point. It can be shown that $Z_{\mathrm{p}}$ is the solution of the third order equation

$$
Z_{\mathrm{p}}{ }^{3}+a_{1} Z_{\mathrm{p}}^{2}+a_{2} Z_{\mathrm{p}}+a_{3}=0
$$

where

$$
\begin{aligned}
a_{1}= & \left(18 C_{2}+6 C_{5} C_{1}-12 C_{1}+24 C\right) / 10 C_{1} \\
a_{2}= & \left(-12 C_{2} C_{5}-6 B+12 C_{2}+C_{6}\right) / 10 C_{1} \\
a_{3}= & \left(-C_{5} C_{6}+6 C_{2}+3 C_{5} C_{1}\right. \\
& \left.+6 C_{5} C_{2}+6 A-C_{6}\right) / 10 C_{1}
\end{aligned}
$$

The valid solution to equation (45) is given by

$$
\begin{aligned}
& Z_{\mathrm{p}}=\mathrm{E}+\mathrm{F}-a_{1} / 3 \quad \text { if } H>0 \\
& Z_{\mathrm{p}}=2 E-a_{1} / 3 \quad \text { if } H=0 \\
& Z_{\mathrm{p}}=2 \sqrt[3]{ } M \cos (\theta / 3+4 \pi / 3)-a_{1} / 3 \text { if } H<0
\end{aligned}
$$

where

$$
\begin{aligned}
H & =q^{2} / 4+p^{3} / 27 ; \quad p=a_{2}-a_{1}{ }^{2} / 3 ; \\
q & =a_{3}-a_{1} a_{2} / 3+2 a_{1}^{3} / 27 ; \quad M=\sqrt{ }\left(-p^{3} / 27\right) ; \\
\cos \theta & =-q / 2 M ; \quad E=\sqrt{ }\left[-q / 2+\sqrt{ }\left(q^{2} / 4+p^{3} / 27\right)\right] ; \\
F & =3\left[-q / 2-\sqrt{ }\left(q^{2} / 4+p^{3} / 27\right)\right]
\end{aligned}
$$

